\title{
Studi Kelayakan Usahatani Kelor dan Kelapa Pandan Wangi pada PT. Bali Agro Investama Unit Perkebunan Penyaringan, Jembrana
}

\author{
Feasibility Study of Moringa and Pandan Wangi Coconut Farm \\ at PT. Bali Agro Investama Penyaringan Plantation Unit, Jembrana \\ Putu Sri Adnyasari ${ }^{*}$ \\ IGAA Ambarawati \\ I Wayan Budiasa \\ Magister Agribisnis, Pascasarjana Universitas Udayana, Bali, Indonesia \\ "Email: adnyasari@yahoo.com
}

\begin{abstract}
PT. Bali Agro Investama, the filtering plantation unit, Jembrana, is one of the ones that has high potential in the development of Moringa and fragrant pandan coconut. This study aims to (1) analyze the feasibility of moringa and coconut farming at PT. Bali Agro Investama; (2) To analyze the feasibility of moringa and coconut farming at PT. Bali Agro Investama. The data used are primary data and secondary data. Designed with descriptive analysis and business feasibility analysis using investment criteria, namely NPV (Net Present Value (NPV)), IRR (Internal Rate of Return (IRR)), Net Benefit-Cost Ratio (Net B/C), payback period, and analysis sensitivity. Data were collected through in-depth interviews, observation, documentation, and literature study. There are two variables in this study, namely the benefits and costs variables. The results of research on non-financial aspects where this company meets five aspects, namely legal aspects, marketing aspects, management aspects, and technical aspects. Business feasibility analysis using investment criteria obtained the following results (1) NPV > 0 (2) IRR > 1\%. (3) Net B/C > 1. (4) Payback period without bank financing is 6.85 years and with bank financing is 7.52 years. Based on the results of sensitivity analysis, this project is sensitive to changes in operating costs and changes in revenue. From the results of this study it can be concluded that the farming of Moringa and Pandan Fragrant Coconut at PT. BAI deserves to be run. The results of this study are expected to be a reference for those in need.
\end{abstract}

Key words : Moringa, pandanus fragrant coconut, feasibility study, sensitivity analysis.

\begin{abstract}
ABSTRAK
PT. Bali Agro Investama unit perkebunan Penyaringan, Jembrana salah satu yang memiliki potensi tinggi dalam pengembangan kelor dan kelapa pandan wangi. Penelitian ini bertujuan untuk (1) Menganalisis kelayakan usahatani kelor dan kelapa pada PT. Bali Agro Investama; (2) Untuk menganalisis kelayakan usahatani kelor dan kelapa pada PT. Bali Agro Investama. Data yang digunakan yaitu data primer dan data sekunder. Dirancang dengan analisis deskriptif dan analisis kelayakan usaha menggunakan kriteria investasi yaitu NPV (Net Present Value $(N P V))$, IRR (Internal Rate of Return (IRR)), Net Benefit-Cost Ratio (Net B/C), payback period, serta analisis sensitivitas. Data dikumpulkan melalui wawancara mendalam, observasi, dokumentasi, dan studi pustaka. Adapun variabel dalam penelitian ini ada dua yaitu variabel manfaat dan biaya. Hasil penelitian pada aspek non finansial dimana perusahaan ini memenuhi kelima aspek yaitu aspek hukum, aspek pemasaran, aspek manajemen, dan aspek teknis.
\end{abstract}


Analisis kelayakan usaha menggunakan kriteria investasi didapat hasil yaitu sebagai berikut (1) $N P V>0$ (2) IRR $>1 \%$. (3) Net $B / C>1$. (4) Payback period tanpa pembiayaan bank selama 6,85 tahun dan dengan pembiayaan bank selama 7,52 tahun. Berdasarkan hasil analisis sesitivitas, proyek ini sensitif terhadap perubahan biaya operasional dan perubahan penerimaan. Dari hasil penelitian ini dapat disimpulkan bahwa usahatani kelor dan kelapa pandan wangi di PT. BAI layak untuk dijalankan. Hasil penelitian ini diharapkan dapat menjadi referensi bagi pihak yang membutuhkan.

Kata kunci : Kelor, kelapa pandan wangi, studi kelayakan, analisis sensitivitas.

\section{PENDAHULUAN}

\section{Latar Belakang}

Tanaman perkebunan seperti kelor merupakan komoditi yang baik untuk dibudidayakan karena memiliki nilai ekonomi yang tinggi. Potensi pengembangan komoditi yang memiliki nilai jual tinggi baik adanya guna produk pertanian memiliki daya saing yang tinggi dan adanya peningkatan kesejahteraan petani tersebut (Subowo, 2009).

Begitupula dengan komoditi perkebunan kelapa. Indonesia masuk ke dalam International Coconut Community. ICC saat ini memiliki 19 negara anggota penghasil kelapa yang menguasai lebih dari 90 persen produksi kelapa dunia dan ekspor produk kelapa (ICC, 2020). Salah satu kelapa yang memiliki potensi tinggi untuk dikembangkan yaitu Kelapa Pandan Wangi. Kelapa pandan wangi adalah salah satu kelapa eksotik dengan karakter spesifik pada buahnya. Aroma wangi pandan pada sabut air dan daging buahnya serta citarasa pandan dan manis pada air dan daging buahnya menjadi ciri khas kelapa yang diketahui aslinya dari Thailand dengan nama 'Aromatic Nam Hom Coconuts' (Dinas Perkebunan Sumut, 2020).

PT. Bali Agro Investama unit perkebunan Desa Penyaringan, Jembrana salah satu yang memiliki potensi tinggi dalam pengembangan kelor dan kelapa pandan wangi di Bali. Dalam pengembangan kelor dan kelapa tersebut, PT. Bali Agro Investama yang nantinya akan sebagai management. Jumlah lahan yang akan diusahatanikan yaitu $3 \mathrm{Ha}$. Meskipun tanaman kelor dan kelapa pandan wangi memiliki banyak manfaat dan memiliki keuntungan yang tinggi dalam produksinya, tetapi perlu adanya analisis untuk mengetahui kelayakan dari usahatani ini dari aspek finansial dan non finansial. Dengan analisis aspek finansial akan diketahui manfaat dan biaya dari usahatani ini. Aspek non finansial terdiri dari aspek hukum, aspek pasar dan pemasaran, aspek teknis dan operasional.

\section{Tujuan Penelitian}

Tujuan penelitian dalam penelitian ini adalah sebagai berikut: Untuk menganalisis kelayakan usahatani kelor dan kelapa pandan wangi pada PT. Bali Agro Investama unit perkebunan Penyaringan ditinjau dari aspek non finansial dan menganalisis kelayakan usahatani kelor dan kelapa pandan wangi pada PT. Bali Agro Investama unit perkebunan Penyaringan ditinjau dari aspek finansial. 


\section{METODOLOGI PENELITIAN}

Penelitian ini dilakukan pada PT. Bali Agro Investama unit perkebunan Penyaringan, Jembrana. Penelitian ini dilaksanakan bulan Januari sampai Juni 2021. Pemilihan lokasi penelitian ini dilakukan secara sengaja (purposive) dengan pertimbangan: 1) Adanya proyek pengembangan kelor dan kelapa pandan wangi di PT. Bali Agro Investama unit perkebunan Penyaringan, 2) Adanya operasional, kelompok tani, dan investor yang saling bersinergi dalam pengembangan usahatani kelor dan kelapa pandan wangi.

Data dalam penelitian ini bersumber dari data primer dan sekunder. Penelitian ini dirancang menggunakan analisis deskriptif dan analisis kelayakan. Analisis kelayakan analisis jangka panjang menggunakan analisis NPV (Net Present Value), IRR (Internal Rate of Return), Net B/C Ratio, payback period, dan analisis sensitivitas.

Tabel 1. Variabel Penelitian dan Pengukuran

\begin{tabular}{|c|c|c|c|c|}
\hline No & Variabel & Indikator & Parameter & Pengukuran \\
\hline \multirow{2}{*}{1} & \multirow{2}{*}{ Manfaat } & Kuantitas Produk & $\begin{array}{l}\text { Jumlah produksi daun kelor } \\
\text { per tahun }\end{array}$ & $\mathrm{Kg}$ /tahun \\
\hline & & Harga produk & $\begin{array}{l}\text { Rata-rata harga sepanjang } \\
\text { tahun. }\end{array}$ & $\mathrm{Rp} / \mathrm{Kg}$ \\
\hline \multirow[t]{13}{*}{2} & Biaya & Biaya Investasi & & \\
\hline & & a. Hidram dan asesoris & Rata-rata harga hidram & Rp/unit \\
\hline & & b. Sumur bor dan asesoris & Rata-rata harga sumur bor & Rp/unit \\
\hline & & $\begin{array}{l}\text { c. Instalasi power sumur } \\
\text { bor dan asesoris }\end{array}$ & $\begin{array}{l}\text { Rata-rata harga instalasi } \\
\text { sumur bor }\end{array}$ & Rp/unit \\
\hline & & $\begin{array}{l}\text { d. Instalasi irigasi } \\
\text { perpipaan dan asesoris }\end{array}$ & $\begin{array}{l}\text { Rata-rata harga irigasi } \\
\text { perpipaan }\end{array}$ & Rp/unit \\
\hline & & & Rata-rata harga tangki air 550 & \\
\hline & & e. Tangki air 5500L & & Rp/unit \\
\hline & & f. Biaya kontruksi/instalasi & Rata-rata biaya instalasi & Rp/unit \\
\hline & & g. Peralatan & Rata-rata biaya peralatan & Rp/unit \\
\hline & & Biaya Operasional & & \\
\hline & & a. Bibit kelor dan kelapa & Rata-rata harga per unit & Rp/unit \\
\hline & & b. Pupuk & Rata-rata biaya pupuk & Rp/unit \\
\hline & & c. Tenaga kerja & Rata-rata biaya tenaga kerja & $\mathrm{Rp} / \mathrm{HOK}$ \\
\hline
\end{tabular}

Asumsi merupakan anggapan dasar dalam suatu penelitian yang diyakini kebenarannya oleh peneliti. Asumsi dalam penelitian ini adalah sebagai berikut:

1. Kelapa pandan wangi dengan jarak tanam $8 \times 8$ dengan jumlah pohon 138 pohon/ha.

2. Kelor daun dengan jarak tanam $1 \times 0,5$ dengan jumlah pohon 12.000 pohon/ha.

3. Rata-rata produksi tahun pertama yaitu $0,3 \mathrm{~kg} / \mathrm{pohon}$.

4. Rata-rata produksi tahun kedua yaitu $0,4 \mathrm{~kg} /$ pohon.

5. Rata-rata produksi tahun ketiga dan seterusnya yaitu $0,5 \mathrm{~kg} /$ pohon.

6. Jumlah pohon kelor yang dipanen perhari pada tahun pertama, kedua dan ketiga yaitu 330 pohon. 
7. Siklus panen yaitu 35 hari, sedangkan siklus (frekuensi) panen per pohon/tahun yaitu 10,4 kali/tahun.

8. Jumlah produksi daun kelor basah yang dibeli pada tahun pertama yaitu $34.650 \mathrm{~kg} / \mathrm{tahun}$.

9. Jumlah produksi daun kelor basah yang dibeli pada tahun kedua yaitu $46.200 \mathrm{~kg} / \mathrm{tahun}$.

10. Jumlah produksi daun kelor basah yang dibeli pada tahun ketiga dan seterusnya yaitu $57.750 \mathrm{~kg} / \mathrm{tahun}$.

11. Kelapa pandan wangi di produksi pada tahun ketiga dengan jumlah produksi 6.900 butir.

12. Jumlah produksi kelapa pandan wangi pada tahun keempat yaitu 13.800 butir.

13. Jumlah produksi kelapa pandan wangi pada tahun kelima dan seterusnya yaitu 17.250 butir.

14. Asumsi harga daun kelor yaitu Rp 4.500/kg.

15. Asumsi harga kelapa pandan wangi yaitu Rp 10.000/butir.

Data yang dipergunakan dalam penelitian ini adalah data kuantitatif dan kualitatif. Data kuantitatif adalah data berbentuk angka yang memiliki satuan hitung atau diukur seperti luas lahan, jumlah produksi dan penjualan, harga jual, biaya bibit, biaya pupuk, biaya tenaga kerja, biaya penyusutan alat, serta biaya lain-lain.

Data kualitatif adalah data yang tidak berbentuk angka, tetapi data yang berupa keterangan atau informasi seperti informasi tentang aspek hukum, aspek pasar dan pemasaran, aspek teknis dan operasional, dan aspek manajemen dan operasional. karakteristik responden, kendala teknis maupun non teknis yang dihadapi petani kelor mencakup budidaya kelor dan kelapa pandan wangi yang dilakukan di PT. Bali Agro Investama unit perkebunan Penyaringan, Jembrana. Pada aspek keuangan, yaitu adanya penilaian kelayakan investasi yang digunakan analisis manfaat biaya yang terdiri dari NPV, IRR, dan Net B/C. Berikut rumus-rumus yang digunakan:

\section{Metode Net Present Value (NPV)}

$\sum_{t=1}^{t=n}=\frac{B_{t}-C_{t}}{(1+i)^{t}} \quad($ Gitinger, 1986)

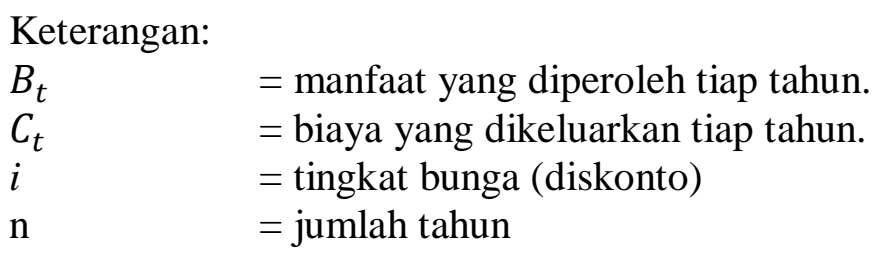

Pengambilan keputusan apakah suatu usulan proyek investasi diterima atau ditolak jika menggunakan metode Net Present Value (NPV) kita bandingkan nilai NPV tersebut dengan nilai nol. Apabila NPV > 0 atau positif, maka rencana investasi layak diterima, sebaliknya apabila NPV < 0 atau negative, maka rencana investasi tidak layak diterima atau ditolak. Begitupula dengan NPV=0, yang berarti rencana investasi hanya balik modal (tidak untung dan tidak rugi).

\section{Metode Internal Rate of Return (IRR)}

$\sum_{t=1}^{t=n}=\frac{B_{t}-C_{t}}{(1+i)^{t}}=0$ (Gitinger, 1986)

Keterangan:

$B_{t} \quad=$ manfaat yang diperoleh tiap tahun.

$C_{t} \quad=$ biaya yang dikeluarkan tiap tahun. 
$\begin{array}{ll}i & =\text { tingkat bunga (diskonto) } \\ \mathrm{n} & =\text { jumlah tahun }\end{array}$

3. Net B/C

Net $B / C=\frac{\sum_{t=1}^{n} \frac{B_{t}-C_{t}}{(1+i)^{t}}}{\sum_{t=1}^{n} \frac{C_{t}-B_{t}}{(1+i)^{t}}} \quad \begin{aligned} & \left(B_{t}-C_{t}>0\right) \\ & \cdots \ldots \ldots \ldots \ldots\end{aligned}$

Keterangan:

$B_{t}=$ manfaat yang diperoleh tiap tahun.

$C_{t} \quad=$ biaya yang dikeluarkan tiap tahun.

$i \quad=$ tingkat bunga (diskonto)

$\mathrm{t} \quad=1,2, \ldots ., \mathrm{n}$

\section{Payback Period}

Periode pembayaran kembali adalah lamanya waktu yang diperlukan untuk pengembalian modal investasi yang dikeluarkan . Apabila waktu pengembalian lebih cepat maka usaha/proyek tersebut semakin baik untuk dikembangkan, begitupula sebaliknya. Payback period dirumuskan sebagai berikut (Sarma, 2010):

$$
\mathrm{PP}=\mathrm{I} / \mathrm{E}
$$

Keterangan :

I : investasi awal.

E :proyeksi arus kas bersih per tahun dari investasi.

PP : Payback Period dinyatakan dalam tahun.

\section{Analisis sensitivitas}

Analisis sensitivitas adalah suatu analisa untuk dapat melihat pengaruh- pengaruh yang akan terjadi akibat keadaan yang berubah-ubah (Gittinger 1986). Semua proyek harus diamati melalui Analisa sensitivitas. Pada bidang pertanian, proyek-proyek sensitive berubah-ubah akibat empat masalah utama.

1. Harga

2. Keterlambatan pelaksanaan

3. Kenaikan biaya

4. Hasil

\section{HASIL DAN PEMBAHASAN}

\section{Aspek Non Finansial}

1. Aspek Hukum

Bali Agro Investama yang sudah berdiri sejak tahun 2020 ini menggunakan badan hukum perseroan terbatas (PT). Perusahaan ini nantinya akan mencari investor untuk mengembangkan usahatani kelor dan kelapa genjahnya. Dengan skala yang cukup luas, maka dari itu perusahaan ini berbentuk perseroan terbatas. Perusahaan ini berbentuk perseroan terbatas (PT) secara legal dimana terbitnya akta pendirian PT yang dilakukan di notaris.

\section{Aspek Pasar dan Pemasaran}

Hasil output dari produksi di perusahaan PT. Bali Agro Investama yaitu daun kelor dan kelapa pandan wangi. Daun kelor sendiri nantinya beberapa akan digunakan sendiri, diproduksi Kembali menjadi tepung kelor. Dengan pasar nasional dan internasional. Karena permintaan 
tepung kelor yang tinggi. Pada umumnya, tepung kelor akan diolah Kembali, dimana tepung kelor dapat menjadi berbagai produk olahan. Dengan harga daun kelor Rp 4.500/kg.

Sedangkan hasil produksi dari tanaman kelapa pandan wangi yaitu buah kelapanya. Kelapa ini memiliki ciri khas pandan wanginya sehingga kelapa ini memiliki banyak penggemar. Diluar negeri, kelapa ini sudah sangat popular dengan harga yang cukup tinggi. Potensi pasar dari kelapa genjah yaitu dengan target produksi 16.000 butir per hektar per tahun. Dengan peluang pasar harga Rp 10.000/butir.

Potensi pasar ekspor kelor menjanjikan dalam pasar internasional, sehingga tanaman tersebut memiliki peluang ekonomi yang besar untuk dibudidayakan. Permintaan dunia terhadap kelor sangat tinggi, namun produksi nya yang masuk sedikit untuk memenuhi permintaan pasar. Begitupula dengan kelapa pandan wangi, peluang pasar kelapa pandan wangi semakin terbuka dan pangsa pasarnya besar.

\section{Aspek Teknis dan Operasional}

Aspek teknis berkaitan dengan input proyek dan ouput yang berupa barang dan jasa. Input yang dimaksud yaitu penyediaan bahan, sedangkan output yaitu berupa hasil produksi. Persediaan bibit dari kelor yaitu didapat dari berbagai daerah, salah satunya adalah dari Sumbawa (NTT). Sedangkan bibit dari kelapa genjah didapat dari daerah Sumatera.

Bibit-bibit tersebut akan ditanam pada area 6 ha, ditanam secara bertahap tiap tahunnya. Setelah ditanam, kelor dapat dipanen setelah berumur 6-12 bulan. Sedangkan kelapa genjah dapat dipanen setelah berumur 3-5 tahun. Selanjutnya hasil output yaitu berupa daun kelor serta buah kelapa genjah yang siap untuk dipasarkan ke konsumen. Jarak tanam kelor adalah panjang 1 meter dan lebar 0,5 meter. Sedangkan jarak tanam kelapa yaitu 8 x 8 meter

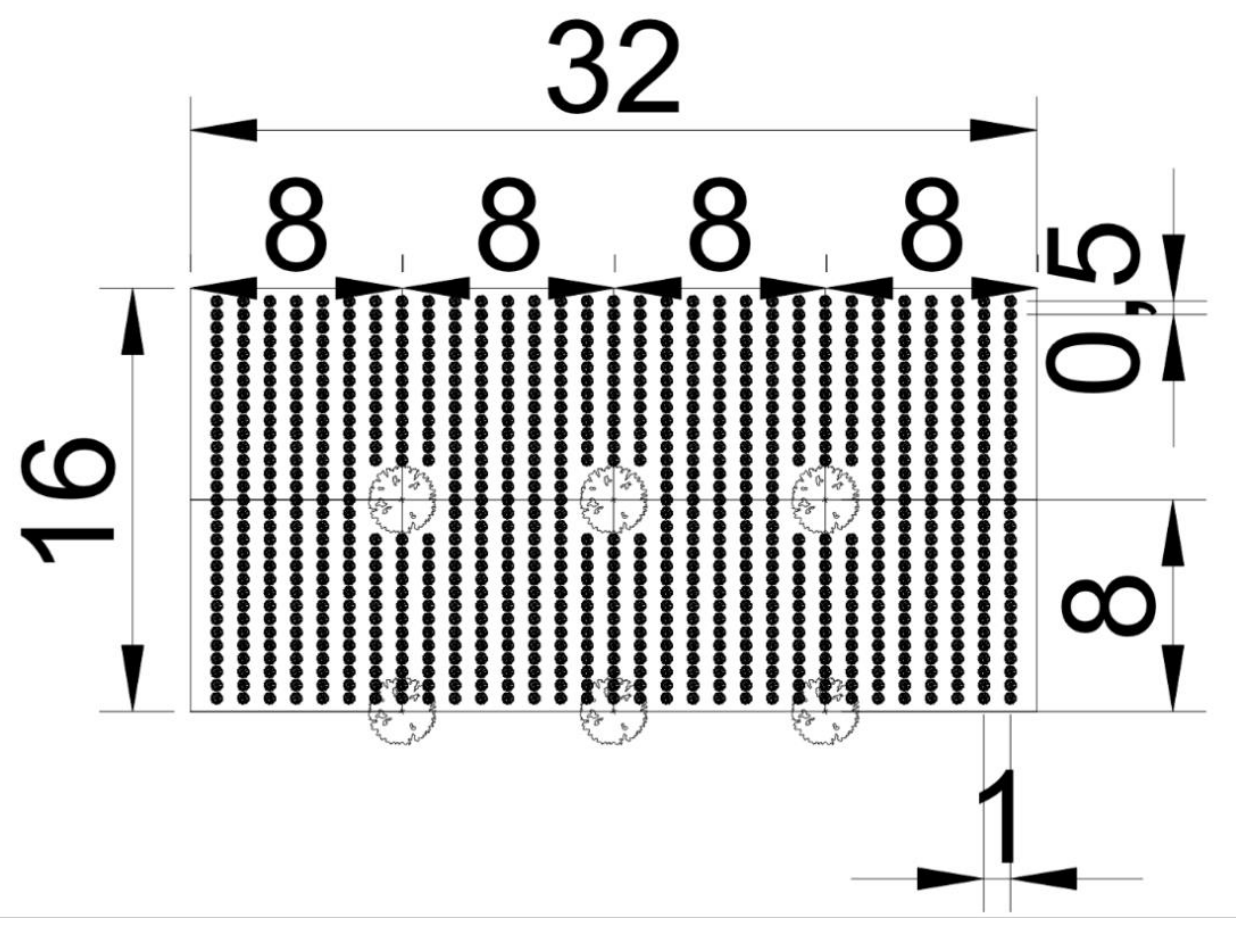

Gambar 1. Pola Tanam Kelor dan Kelapa pada PT. Bali Agro Investama unit Perkebunan Penyaringan, Jembrana 


\section{Aspek Manajemen dan Organisasi}

Sumber daya manusia sangat penting perannya dalam suatu organisasi sehingga rencana dari suatu perusahaan dapat berjalan dengan baik dan mendapatkan profit. Dalam struktur organisasi terdiri dari: komisaris, direktur utama, divisi projects, divisi admin dan accounting, dan divisi marketing, project managers, SDM, dan Accounting

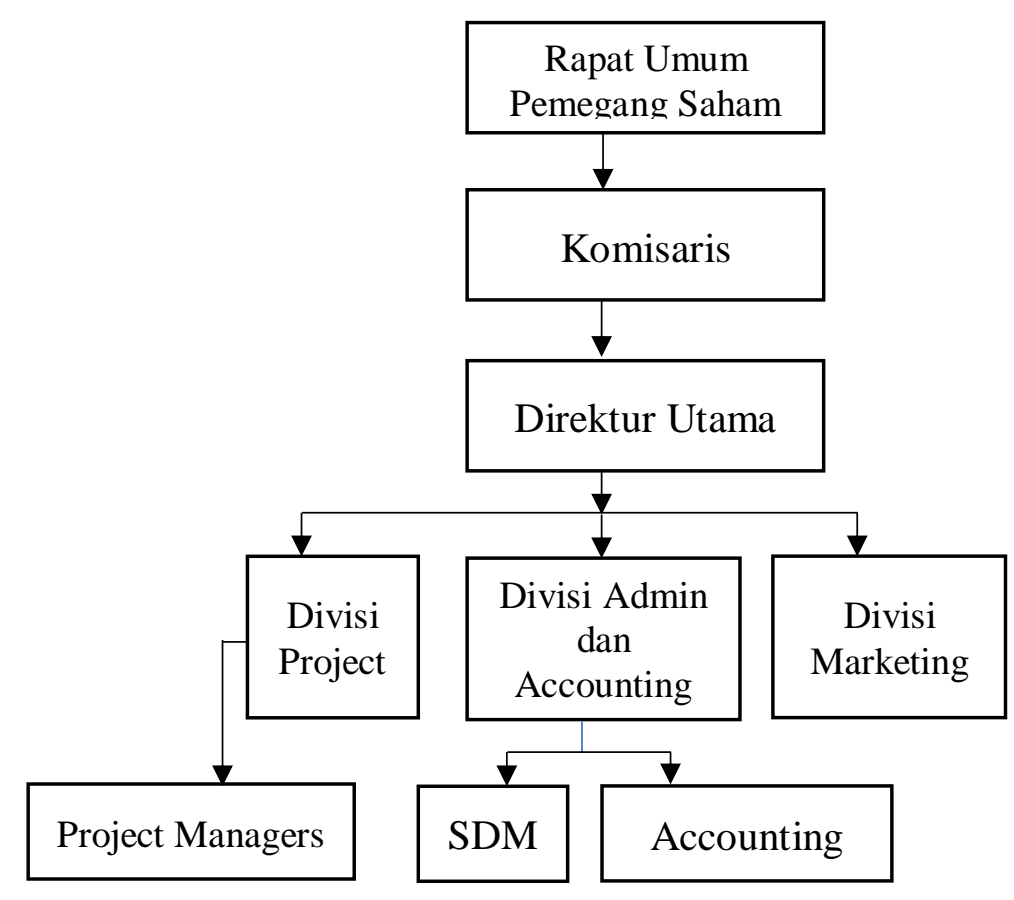

Gambar 2. Struktur Organisasi PT. Bali Agro Investama

\section{Aspek Finansial}

Aspek finansial yang terdiri dari NPV, IRR, Net B/C, payback period, dan Analisis sensitivitas. Aspek tersebut yang biasanya digunakan untuk meihat layak atau tidaknya suatu proyek usahatani kelor dan kelapa untuk dilaksanakan.

\section{Net present value (NPV)}

Suatu proyek akan dikatakan layak apabila nilai NPV $>0$. Hasil perhitungan NPV untuk usahatani kelor dan kelapa, dalam perhitungan tanpa pembiayaan maupun dengan pembiayaan bernilai lebih dari nol. NPV dengan pembiayaan yang memiliki nilai 757.545.091,57 dan tanpa pembiayaan juga memiliki nilai yang sama yaitu 757.545.091,57. Oleh karena itu, usahatani ini layak untuk dijalankan di PT Bali Agro Investama, unit kebun Penyaringan.

\section{Net benefit cost ratio (Net $\mathrm{B} / \mathrm{C}$ ratio)}

Suatu proyek harus memiliki nilai Net B/C > 1. Usahatani kelor dan kelapa memiliki nilai Net B/C tanpa pembiayaan bank sebesar 2,067 Artinya, apabila usahatani kelor dan kelapa dijalankan tanpa pembiayaan dari bank, setiap Rp 1.000,00 biaya yang dikeluarkan akan menghasilkan pendapatan sebesar Rp 2.067 Sedangkan sebaliknya, nilai net B/C dengan pembiayaan adalah mencapai 2,527 Ketika usahatani kelapa dan kelor dibantu dengan pembiayaan bank, maka setiap biaya Rp 1.000,00 pendapatan meningkat sampai Rp 2.527 Oleh karena itu, dengan perhitungan diatas. Maka proyek usahatani kelor dan kelapa di PT. Bali Agro Investama, Unit Penyaringan layak diusahakan. 


\section{Internal rate of return (IRR)}

Suatu proyek dikatakan layak apabila nilai internal rate of return IRR harus melebihi rata-rata suku bunga kredit yang berlaku di bank. Nantinya IRR akan menggambarkan suatu proyek dalam kemampuannya dalam membayar bunga bank ketika proyek memilih adanya pembiayaan dari bank. Hasil penelitian pada usahatani kelor dan kelapa ini diperoleh nilai IRR adalah $42,30 \%$ dalam perhitungan tanpa pembiayaan bank. Sedangkan dalam perhitungan dengan pembiayaan bank menjadi 56,12\%. Internal rate of return (IRR) menjelaskan bagaimana apabila suatu proyek usahatani kelor dan kelapa menggunakan modal sendiri, namun dalam kondisi tertentu saat ada perubahan meminjam ke bank, maka suku bunga maksimal yang mampu dibayar adalah $42,30 \%$. Sedangkan, apabila proyek usahatani tersebut sudah menggunakan fasilitas pembiayaan bank dan akan menambahkan kredit Kembali, maka suku bunga maksimal yang mampu dibayar sebesar 56,12\% Suku bunga saat ini yaitu 24,25\% .

\section{Payback Period}

Payback period menggambarkan waktu yang diperlukan dalam pengembalian modal yang dikeluarkan untuk investasi. Berdasarkan perhitungan pada sub bab 5 dimana nilai yang didapatkan apabila proyek usahatani kelor dan kelapa dalam keadaan tanpa pembiayaan waktu yang diperlukan untuk pengembalian investasi dari pendapatan yaitu 6,85 tahun. Sedangkan waktu yang diperlukan apabila proyek usahatani kelor dan kelapa menggunakan pembiayaan dari bank, maka waktu pengembalian investasi yaitu 7,52 tahun.

\section{Analisis Sensitivitas}

Penurunan penerimaan 20\% dapat mempengaruhi usahatani kelor dan kelapa pandan wangi dalam beroperasi. NPV pada penerimaan turun $20 \%$ tanpa pembiayaan dan dengan pembiayaan memiliki nilai 83.538.056,466. Sedangkan Net B/C ratio tanpa pembiayaan memiliki nilai $1,211 \%$ dan dengan pembiayaan memiliki nilai $0,99 \%$. IRR tanpa pembiayaan memiliki nilai $26,30 \%$ dan dengan pembiayaan dengan nilai $27,06 \%$. Keduanya memiliki nilai lebih dari suku bunga yaitu $24,25 \%$.

Begitu pula dengan peningkatan biaya operasional sebesar $20 \%$ berpengaruh terhadap usahatani kelor dan kelapa dalam beroperasi. NPV tanpa pembiayaan dan dengan pembiayaan memiliki nilai 491.682.761,62. Dimana NPV memiliki nilai lebih dari 1 sehingga usahatani kelor dan kelapa layak untuk diusahakan. Net B/C tanpa pembiayaan memiliki nilai 1,68 sedangkan dengan pembiayaan memiliki nilai 1,49 . IRR tanpa pembiayaan memiliki nilai $42,30 \%$ dan dengan pembiayaan memiliki nilai 56,12\%. Keduanya memiliki nilai yang lebih dari suku bunga kredit yaitu $24,25 \%$. Dari kedua perubahan penerimaan dan biaya operasional tersebut, yang paling sensitive terhadap perubahan yaitu pada penerimaan yang turun $20 \%$ dapat dilihat pada NPV yang memiliki nilai lebih kecil dibandingkan dengan biaya operasional yang turun $20 \%$.

\section{SIMPULAN DAN SARAN}

\section{Simpulan}

Kesimpulan yang dapat diambil dari hasil penelitian dan pembahasan adalah:

Pada aspek non finansial, usahatani kelor dan kelapa ini berbadan hukum perseroan terbatas (PT). Perusahaan ini nantinya akan mencari investor untuk mengembangkan usahatani kelor dan kelapa genjahnya. Dengan skala yang cukup luas, maka dari itu perusahaan ini berbentuk perseroan terbatas. Pada aspek finansial, usahatani kelor dan kelapa ini layak untuk diusahakan 
dikarenakan memenuhi kriteria investasi. Dimana NPV memiliki nilai leboh dari nol, net B/C ratio lebih dari satu, dan IRR memiliki nilai lebih dari suku bunga yang berlaku yaitu $24,25 \%$. Pada analisis sensitivitas, usahatani kelor dan kelapa ini sensitive terhadap perubahan penerimaan dan biaya operasional.

\section{Saran}

Sebaiknya usahatani kelor dan kelapa pada PT. Bali Agro Investama terus dikembangkan, karena dilihat dari segi peluang pasar usahatani ini bisa menjadi prospek usaha yang baik. Pemanfaatan dan pengembangan lahan produksi yang lebih baik agar nantinya perusahaan dapat memenuhi permintaan pasar.

\section{DAFTAR PUSTAKA}

Agrowindo. 2015. Peluang Usaha Budidaya Daun Kelor dan Analisis Usahanya. http://www.agrowindo.com/peluang-usaha-budidaya-daun-kelor-dan- analisa-usahanya. Diunduh 18 Oktober 2019.

Anggriawan dan Indrawati. 2013 Peranan Komoditi Gambir Terhadap Perekonomian Kabupaten Lima Puluh Kota Provinsi Sumatera Barat. Jurnal Ekonomi Vol. 21 No. 2 Juni 2013. Fakultas Ekonomi Universitas Riau Km 12,5 Panam. Riau. https://media.neliti.com/media/publications/8688-ID-peranan-komoditi-gambir-terhadapperekonomian-kabupaten-lima-puluh-kota-provinsi.pdf. Diunduh 4 Desember 2020.

Animashaun, J.O and Toye, A.A. 2013. Feasibility Analysis of Leaf-Based Moringa oleifera Plantation in the Nigerian Guinea Savannah: Case Study of University of Ilorin Moringa Plantation. Agrosearch. Department of Agricultural Economics \& Farm Management, University of Ilorin, Nigeria. Nigeria.

Badan Litbang Kementan. 2015. Praktek Budidaya Pertanian Yang Baik (Good Agricultural Practices). Kementrian Pertanian. http://hortikultura.litbang.pertanian.go.id/Modul\%20PTT/Cabai/Budidaya\%20Pertanian \%20Umum.pdf. Diunduh pada 20 April 2020.

Budiasa. 2017. Perencanaan dan Evaluasi Proyek Agribisnis. Udayana Press, Bali.

Balai Penelitian Tanaman Palma. 2015. Petunjuk Teknis Budidaya Tanaman Kelapa Dalam. Badan Penelitian dan Pengembangan Pertanian Pusat Penelitian dan Pengembangan Perkebunan. Kementrian Pertanian. Manado.

Darwansyah. 2013. Peran Struktur Organisasi dan Sistem Remunerasi dalam Meningkatkan Kinerja. Jurnal Ekobis Vol. 14 No. 2. Universitas Islam Sultan Agung. http://jurnal.unissula.ac.id/index.php/ekobis/article/viewFile/572/474 . Diunduh 5 April 2021.

Gittinger JP. 1986. Analisa Ekonomi Proyek_Proyek Pertanian. UI Press. Jakarta.

Hartanto. 2018. Biaya Modal (Cost of Capital). https://docplayer.info/72922394-Biaya-modalcost-of-capital.html diunduh pada 1 Juni 2021. 
Hatmaninggita. 2008. Instrumen Penelitian (Pedoman Wawancara). Fisip. Universitas Indonesia. http://lib.ui.ac.id/file?file=digital/124258 SK\%20010\%2008\%20Hat\%20a\%20-\%20Analisis\%20kepemimpinan-Lampiran.pdf . Diunduh 10 September 2020.

ICC. 2020. Outlook 2020 dan Prospek Pasar Kelapa Dunia. ICC Secretariat. Jakarta.

Intergrated Taxonomy Information System. 2017. Moringa oleifera Lamk. Taxonomy Serial No.503874.https://www.itis.gov/servlet/SingleRpt/SingleRpt?search topic=TSN\&search _value=503874\#null. Diunduh 20 April 2020.

Isnan W. dan Nurhaedah M. 2017. Ragam Manfaat Tanaman Kelor (Moringa oleifera Lamk.) Bagi Masyarakat. Info Teknis Eboni Vol. 14 No. 1, Juli 2017 : 63-75. http://balithutmakassar.org. diunduh 18 Oktober 2019.

Ismail. 2020. PT (Perseroan Terbatas): Pengertian, Jenis, Ciri-Ciri, dan Unsur-Unsur PT). https://accurate.id/bisnis-ukm/pengertian-pt/ diunduh pada 1 Juni 2021.

KBRI. 2016. Potensi Ekpor Produk Kelapa di Thailand. Atase Perdagangan Kedutaan Besar Republik Indonesia Bangkok. http://djpen.kemendag.go.id/membership/data/files/65b73produk-kelapa.pdf. Diunduh 4 Desember 2020.

Kementrian Perindustrian. 2010. Roadmap Industri Pengolahan Kelapa. Jakarta.

Krisnadi, A.D. 2015. Kelor Super Nutrisi. Blora. http://kelorina.com/ebook.pdf. Diunduh 18 oktober 2019.

Moleong. 2006. Metodologi Penelitian Kualitatif. PT. Remaja Rosdakarya. Bandung.

Nuhung. 2014. Strategi dan Kebijakan Pertanian dalam Perspektif Daya Saing. Penerbit Rineka Cipta. Jakarta.

Pangestu dan Aulia. 2017. Hukum Perseroan Terbatas dan Perkembangannya di Indonesia. Business Law Review (Volume Three). Jakarta.

Saeri. 2018. Usahatani dan Analisisnya. Universitas Wisnuwardhana Malang Press. Malang.

Sarma. 2010. Methods/Criteria of Project Evaluation or Measures of Project Worth of Investment. FA, AAU, Jorhat.

Subowo. 2009. Potensi Pengembangan Komoditas Pertanian Bernilai Ekonomi Tinggi. Jurnal Sumberdaya Lahan Vol. 3 No. 1, Juli 2009.

Sugiyono. 2017. Metode Penelitian Kuantitatif, Kualitatif, dan R\&D. Alfabeta. Bandung.

Utama. 2021. Peluang Bisnis Kelapa Pandan Wangi Thailand Beromzet Rp 1,296 Miliar/Ha/Tahun. https://agrikan.id/peluang-bisnis-kelapa-pandan-wangi-thailandberomzet-rp-1296-miliar-ha-tahun/ diunduh 28 Juni 2021. 
Yani dan Gunawan. 2000. Seri Hukum Bisnis: Perseroan Terbatas. PT. Raja Grafindo Persada. Jakarta.

Yuli. 2019. Kelor (Moringa oleifera) "Si Pohon Ajaib". Pusat Konservasi Tumbuhan Kebun Raya. http://krbogor.lipi.go.id/id/Kelor-Moringa-oleifera-Si-Pohon-Ajaib. Diunduh 18 Oktober 2019.

Wiguna. 2018. Pasar dan Khasiat Kelor. PT Trubus Swadaya. Depok. 